\title{
Analysis of Key Points of Anti-Seepage Technology in Hydraulic Engineering Construction
}

\author{
Pan Guoyong $^{1 *}$, Chen Yixin ${ }^{2}$ \\ ${ }^{1}$ Quality and Safety Service Guarantee Center of Hangzhou Fuyang Water Conservancy and Hydropower Project, Hangzhou City, \\ Zhejiang Province, 311400; \\ ${ }^{2}$ Hangzhou Fuyang River Reservoir Management Center, Hangzhou City, Zhejiang Province, 311400)
}

\begin{abstract}
The water conservancy project is an important infrastructure to ensure people's living standards, which is reflected in the protection of people's lives and property by effectively resisting floods. The anti-seepage technology plays a significant role in affecting the construction quality of water conservancy projects. Under the current strong supervision of water conservancy projects, relevant personnel should pay more attention to the application of anti-seepage technology. From the perspective of actual engineering practice, this paper analyzed the importance of anti-seepage technology, sorted out the causes of leakage, and specifically explored the implementation points of anti-seepage technology in water conservancy project construction.
\end{abstract}

\section{Introduction}

According to various service objects, water conservancy projects can be divided into flood control projects, hydropower projects, farmland irrigation projects, port and waterway projects, and tideland reclamation projects. Different types of projects have different construction problems, but they all have one problem in common, that is, leakage. If there is a leakage problem during the construction, it will not only affect the construction quality and service life of the entire water conservancy project but also endanger people's life and property safety. What's worse, it is not conducive to the stable development of China's society and economy. Therefore, in the new historical era, to better promote the development of water conservancy projects in China, it is necessary for relevant personnel to utilize advanced science and technology to strengthen the implementation of anti-seepage measures through a thorough analysis of water conservancy projects. In addition, it is expected to actively master the key points of anti-seepage construction technology and rationally use it to help improve the overall quality of water conservancy projects [1], thereby providing more support for the safe construction of water conservancy projects.

\section{Cause analysis of leakage problems in water conservancy projects}

\subsection{External factors}

The construction conditions of water conservancy projects are very harsh with long periods and complicated operations. As a result, the construction environment is particularly vulnerable to interfere from external conditions, including extreme weather, topography, and hydrogeology, all of which will adversely affect on-site construction. In case of heavy rainfall, it will cause problems such as large-scale water accumulation on the construction site and poor drainage facilities, resulting in hidden dangers of leakage. Besides, the complexity of geological conditions in some areas has increased the difficulty of implementing anti-seepage measures in construction, leading to frequent leakage problems.

\subsection{Designing factors}

There are many influencing factors in the construction of complex water conservancy projects. Therefore, designers need to conduct a comprehensive survey and analyze the local natural and social environment before they can design a legitimate engineering plan. However, in reality, the designing time is often so tight that the designers fail to conduct a thorough site survey and lack thorough consideration. Accordingly, some of the adopted design schemes are unable to meet the requirements of anti-seepage measures, causing subsequent leakage.

\subsection{Construction factors}

To ensure the construction quality of water conservancy projects, it is necessary to accurately take control of each construction link, not only strictly controlling the construction steps and methods, but also strictly 
controlling the construction team. In the actual construction process, outsourcing or subcontracting is often carried out in various forms. Although subcontracting construction is conducive to accelerate the progress of the project, due to the excessive participation of construction subjects, the anti-seepage technology of different construction subjects is uneven, leading to hidden leakage hazards in the process of project connection and affecting the overall construction quality ${ }^{[2]}$. At the same time, some companies do not pay enough attention to the construction plan, relying only on experience rather than following the standardized operation method to carry out the construction, which lowers the construction operation quality and causes subsequent leakage.

\subsection{Deformation factors}

There are two main reasons for the water seepage caused by the deformation of the water conservancy project. One is caused by the deformation of building materials, and the other is caused by the deformation of the engineering structure. Omissions in construction management or leaks in the storage of construction materials may cause water seepage. For example, in the construction of water conservancy projects, concrete deformation joints are reserved to cope with external stress. When constructing deformation joints, materials with better waterproof performance should be selected as much as possible. However, from the perspective of actual operation, due to the influence of many factors, the entire project did not choose high-quality waterproof materials, eventually causing deformation joint leakage in the entire project.

\subsection{Management \& maintenance factors}

The quality and durability of the project depend on the subsequent operation and maintenance. However, in many cases, water conservancy projects tend to emphasize construction and neglect management. Long-term wear and use may lead to varying degrees of damage and water leakage in hydraulic structures. Failure to check and maintain in time or discover problems may deepen the damage and leakage of the building, and the possibility of major accidents cannot be ruled out.

\section{Application of anti-seepage technology in hydraulic engineering construction}

\subsection{Grouting}

\subsubsection{High-pressure jet grouting}

The application of the high-pressure jet grouting technique is to implement grouting through the high-pressure jet operation. In this way, it can be ensured that the cement slurry and the particles poured into the stratum are effectively fused, and finally, a hard wall-shaped body is formed to achieve the target anti-leakage effect. It can be concluded from practice that this technique has a high application effect and plays an important role in optimizing the overall construction quality of water conservancy projects ${ }^{[3]}$.

\subsubsection{Curtain grouting}

The curtain grouting technique is generally used in the foundation treatment of dam foundations. An underground anti-seepage curtain is formed between the rock mass and the sand gravel to reduce the seepage pressure at the bottom of the dam, which enables to prevent mechanical or chemical piping effect and reduce the seepage flow. To effectively reduce the groundwater leakage of the foundation during operation, the top of the foundation must be connected with the foundation floor, and there must be a certain depth of water barrier at the bottom.

\subsubsection{Fracture grouting}

Fracture grouting is a reinforcement method based on the principle of hydraulic fracturing. A new cut-off wall is formed by drilling holes on the axis of the dam with poor geological conditions and pouring mud under pressure. After conducting fracture grouting along the axis of the dam, the dam body is consolidated into a new cut-off wall under the action of the mud weight and the mutual pressure of the mud and the dam. The wall can block leakage and improve the integrity of the dam body. The fracture grouting has high requirements for operation skills. Operation errors will not only fail to achieve the effect of strengthening the dam but will cause damage to the dam. Therefore, the construction quality must be paid attention to during the grouting process.

\subsection{Cut-off wall}

\subsubsection{Water jetting method}

The application of water jetting in water conservancy projects places high requirements on mechanical equipment, so the following aspects of the preparations must be strictly done in specific construction operations. First, the high-speed water flow is used to cut the soil layer. After the cutting is completed, the wall is slurry-supported as protection. If muck occurs during the process, it needs to be cleaned up in time. Second, the concrete continuous cut-off wall is finally formed by pouring concrete ${ }^{[4]}$. This method is specifically suitable for anti-seepage and interception treatment of sandy soil foundation and is an advanced foundation treatment method with a significant anti-seepage effect.

\subsubsection{Bucket chain engineering method}

The bucket chain excavator is used to take soil from the rotating chain bucket on the pile row, which further 
effectively ensures that the oblique pile row is placed to a certain depth of the wall. When the excavator moves forward, the trench is excavated and then the wall is supported and protected with mud accordingly. The bucket chain method requires very high technical skills, so it is widely used in many different cutoff wall structures. Besides, the grooving depth range of the bucket chain excavator is limited to be within $15 \mathrm{~m}^{[5]}$.

\subsubsection{Saw-type engineering method}

The reciprocating cutting movement with the cutter bar of the sewing machine can ensure a certain degree angle of inclination during engineering construction. The specific cutting movement direction is front, up, and down. Yet, before starting the cutting operation, it is necessary to determine the cutting speed based on the specific conditions of the soil layer. In general, the optimal cutting speed needs to be controlled within the range of $0.8 \sim 1.5 \mathrm{~m}$ per hour. After determining the cutting method and speed, the soil body cut by the saw is discharged out of the trough by the circulation method, and the cut-off wall is formed by pouring plastic concrete. As the width of the cut-off wall is generally between $20 \sim 30 \mathrm{~cm}$, cutting with a sewing machine helps extend the width of the cut-off wall to about $40 \mathrm{~m}$. This can better establish the continuity of trough formation, making the entire project achieve the ideal anti-seepage effect ${ }^{[6]}$.

\subsubsection{Multi-auger deep mixing method}

The application of the multi-auger deep mixing method is simple to operate and reduces the construction cost of the entire project to a certain extent. In addition to reducing engineering costs, it can also reduce construction pollution for the duration of the actual construction. Through the analysis of the previous test operation, it is found that the method has higher groove depth and better compressive strength in the environment of clay and sandy soil. In actual construction operations, multi-auger drilling can be performed at one time, thereby lowering the construction cost of the entire project.

\subsection{Composite geomembrane}

Composite geomembrane is an emerging engineering material, widely used in anti-seepage projects. Because of its extensive application and effectiveness in flood control and rescue projects, it has attracted much attention from engineering and technical personnel. It combines the advantages of geomembrane and geotextile, including the three-layer structure shared by one layer of geomembrane and two layers of geotextile. The material can achieve a very ideal anti-seepage effect with a low cost, light weight and simple structure. Apart from this, it features high strength, good elongation, large deformation modulus, and strong durability.

\section{Analysis of key points of anti-seepage in water conservancy projects}

\subsection{Strict control on the design}

In water conservancy projects, a corresponding and legitimate anti-seepage design plan should be formulated according to the actual hydrogeological conditions, topographic features, and engineering characteristics of the project area. On the one hand, designers must strengthen their cognition and master the key points of the latest anti-seepage treatment technology, so that they can design the most feasible and advanced solutions for different working conditions. On the other hand, it is necessary to ensure that geological surveys are carried out. On-site investigation to understand the actual situation can avoid the unrealistic plan and prevent the omission of some special geological conditions. A good design plan is beneficial to undertaking the later construction of the water conservancy project more orderly.

\subsection{Strict control on the construction}

Due to the complex construction environment of water conservancy projects, the construction unit should strengthen the study and application of construction technology. Standardized operations should be implemented for each anti-seepage construction process, such as the cut-off wall construction process and grouting construction process, to ensure that the construction quality meets the design standards and avoids leakage problems. Besides, the quality of the construction unit team should be enhanced. Only by improving the quality awareness and sense of responsibility of the first-line construction workers, can the construction be rigorous and meticulous.

\subsection{Strict control on the materials}

The quality of anti-seepage materials affects the application effect of anti-seepage construction technology, so the procurement and testing of materials must be checked to ensure that the quality of construction materials meets the construction requirements ${ }^{[7]}$. After completing the design plan of anti-seepage construction, the corresponding materials should be selected according to the design technical indicators. The supervision unit shall strengthen the parallel testing of materials and strictly supervise the use of building materials.

\subsection{Strict control on the maintenance}

Long-term use and wear will inevitably lead to building aging and leakage. Therefore, it is required to strengthen the maintenance of water conservancy projects. On the one hand, it is necessary to strengthen daily inspections. If leakage is found, different solutions should be adopted according to different situations in time to avoid further problems. For example, the concentrated caves appearing 
in the construction of dams can be sealed with concrete and smoothed with cement mortar to improve the smoothness of the dam surface; the surface of the concrete with micro-seepage can be covered with waterproof materials for anti-seepage treatment, which effectively promotes the sustainability of water conservancy projects. On the other hand, to avoid leakage and prolong the service life of water conservancy projects, it is necessary to take preventive measures. If conditions permit, radiographic testing can be used to conduct regular inspections on key parts of water conservancy projects ${ }^{[8]}$. After the crack is found, repair work should be carried out in time to avoid leakage after the crack penetrates.

\subsection{Strict control on the supervision}

Leakage during construction may be related to both objective and subjective factors, such as inadequate human supervision. This requires comprehensive geological surveys and overall planning before construction. During construction, it is essential to strictly implement various quality standards by selecting high-quality construction parties and ensuring the quality of construction materials. Only scientific quality monitoring in place can effectively avoid leakage and ensure the quality of the project.

\section{Conclusion}

In summary, it can be concluded that anti-seepage technology has always been an important part of the construction of water conservancy projects, and the application of anti-seepage technology can effectively reduce the occurrence of engineering risk factors. It is still expected that construction management personnel pay significant attention to detailed quality supervision and full dynamic monitoring of key links, so as to eliminate hidden dangers of leakage in the project and promote the quality of the project. With the continuous development of science and technology in China, anti-seepage technology is constantly improving, but there are still some problems and limitations, so relevant staff still need to continue to explore new techniques, thereby further ensuring the quality of water conservancy projects.

\section{References}

1. Zhang Yue. Analysis of anti-seepage technology in water conservancy project construction[J]. Architectural Engineering Technology and Design, 2019, (30): 2560.

2. Gao Jiandong. Analysis of anti-seepage technology in hydraulic engineering construction technology[J]. Architectural Engineering Technology and Design, 2019, (30): 2396.

3. Mei Shuxia, Liu Jun. Application of anti-seepage technology in water conservancy project construction $[\mathrm{J}]$. Hebei Water Resources,
2020(1):47-48.

4. Wang Zhangtao, Qiao Nan. Analysis of technical schemes and implementation points of anti-seepage construction in water conservancy projects[J]. Technology Innovation and Application, 2017, (13): 56.

5. Ma Jiajia. Application of anti-seepage technology in construction of water conservancy projects[J]. Rural Economy and Science, 2020(22):57-58.

6. Yu Meiting. Analysis of key points of anti-seepage technology in water conservancy project construction[J]. Economy of Hydroenergy, 2018, (3): 85-85.

7. Wei Xiuwu. Discussion on anti-seepage construction technology of water conservancy and hydropower projects[J]. Harnessing the Huaihe River, 2020(09): 57-58.

8. Ma Yuxin. Analysis of anti-seepage technology in hydraulic engineering construction[J]. Groundwater, 2018, 040(003):180-181. 